\title{
FORMAÇÃO CONTINUADA DA EQUIPE GESTORA NA ESCOLA PÚBLICA MUNICIPAL
}

Vanda Moreira Machado Lima, Larissa Teixeira

Faculdade de Ciências e Tecnologia "Júlio de Mesquita Filho" -FCT/UNESP. Curso de Pedagogia, Presidente Prudente SP. Financiamento: Pró-Reitoria de Extensão Universitária- PROEX/UNESP. E-mail: vandalima@fct.unesp.br

\section{RESUMO}

O texto visa apresentar as necessidades formativas da equipe gestora de uma escola pública municipal que subsidiou a elaboração coletiva de uma ação de formação continuada para a melhoria da qualidade do ensino público. A pesquisa se insere na abordagem qualitativa e considerando nossos objetivos os instrumentos para coleta de dados foram: estudo bibliográfico, observação de atividades na identificação das necessidades formativas e participação das ações de formação. Constatamos que a parceria entre a escola pública e a universidade na reflexão das necessidades formativas e na elaboração de uma ação de formação continuada propicia o desenvolvimento profissional de todos os envolvidos sejam os sujeitos da escola ou mesmo da universidade. Verificamos que processos de formação continuada que se fundamentam nas necessidades formativas dos sujeitos envolvidos tendem a ter melhores resultados.

Palavras-chave: Escola Pública Municipal. Gestão democrático participativa. Equipe Gestora. Formação Continuada. Ensino Fundamental.

\section{CONTINUING EDUCATION TEAM MANAGER IN PUBLIC SCHOOL HALL}

\section{ABSTRACT}

This paper aims to provide the training needs the management team of a public school that supported the collective elaboration of an action of continuing education for improving the quality of public. The research falls within the qualitative approach considering our goals instruments for data collection were: bibliographic study, observation of activities in the identification of training needs and interest shares in training. We note that the partnership between the public school and university in the reflection of the training needs and developing an action continuing education fosters the professional development of all those involved are the subjects of the school or university .Verified as continuing education processes that are based on the training needs of those involved tend to have better results .

Keywords: Municipal Public School. Participatory democratic management. Management Team. Continuing Education. Basic Education.. 


\section{INTRODUÇÃO}

A escola, como instituição social, representa o espaço propício para humanização, para formar pessoas capazes de entender seu papel como sujeito histórico e transformador e de compreender criticamente a sociedade em que vive e refletir sobre sua atuação nela. Assim a "escola constitui espaço privilegiado para esse aprendizado, e não apenas para ensinar a ler, a escrever e a contar, habilidades importantes, mas insuficientes para a promoção da cidadania" (LIBÂNEO, OLIVEIRA, TOSCHI, 2003, p. 145). A escola precisar se construir como um centro de debates, de discussões que propiciem infinitos momentos de reflexão, um espaço para formar pessoas críticas e reflexivas, ou seja, compreendemos a escola como excelente espaço de formação continuada para todos os seus profissionais.

Nesse sentido nossa pesquisa geral visa propiciar a reflexão sobre o papel dos gestores escolares na elaboração de projetos que respondam aos desafios do cotidiano escolar. Entretanto, neste texto nosso objetivo é apresentar as necessidades formativas da equipe gestora de uma escola pública municipal que subsidiou a elaboração coletiva de uma ação de formação continuada para a melhoria da qualidade do ensino público.

\section{METODOLOGIA}

A pesquisa se insere na abordagem qualitativa e considerando nossos objetivos os instrumentos para coleta de dados foram: estudo bibliográfico, observação de atividades na identificação das necessidades formativas e participação das ações de formação. Este estudo se desenvolveu junto a equipe gestora (diretora, vice diretora, coordenadora pedagógica e coordenadora do programa de educação integral) de uma escola pública municipal no primeiro semestre de 2014. Está pesquisa foi aprovada pelo Comitê de Ética em Pesquisa (CEP) da nossa unidade.

Mediante 0 estudo bibliográfico conceituamos as idéias chaves da pesquisa apresentada posteriormente: formação continuada; gestão democrática e função da equipe gestora. A observação de atividades na identificação das necessidades formativas ocorreu no início do semestre na semana de planejamento participativo. A participação das ações da formação continuada foi no período de março a julho de 2014, cujos temas foram: indisciplina e planejamento.

\section{RESULTADOS}

Ressaltamos a existência de uma parceria entre a universidade e essa escola pública municipal desde 2011, o que favorece e possibilita o desenvolvimento desta 
pesquisa. Inicialmente apresentamos a identificação das necessidades formativas da equipe gestora que subsidiaram a ação de formação continuada.

\section{NECESSIDADES FORMATIVAS DA EQUIPE GESTORA}

$\mathrm{Na}$ semana do planejamento participativo de 2014 a diretora coordenou a dinâmica que possibilitou reflexões e discussões sobre a identificação das necessidades formativas da escola envolvendo equipe gestora, professores e funcionários.

A dinâmica constituiu-se no primeiro momento em entregar tiras de papel e pincel atômico para que cada sujeito escrevesse suas necessidades visando desenvolver seu trabalho com qualidade na escola. Cada um poderia usar quantas tiras necessitassem, mas deveria escrever uma necessidade em cada tira de papel. Todos escreveram e colavam suas necessidades num grande painel de papel afixado na parede da escola. Posteriormente, começamos o segundo momento da dinâmica, no qual a diretora foi coletivamente com todos os participantes lendo as necessidades, identificando a justificativa e agrupando as por afinidades. Após um longo processo de questionamentos, analises e discussões no coletivo o grupo identificamos três tipos de necessidades: a) necessidades de compras. Constitui-se de comprar pequenos objetos que seriam providenciados pela própria escola, como, por exemplo, balde com divisória, consertos em geral pequenos, indicativos para melhorar a qualidade do giz, colocação de cortinas nas salas, etc.

b) necessidades junto à Secretaria Municipal de Educação. Nesse item tivemos uma lista enorme de necessidades que deveriam ser encaminhadas por ofício à secretária, como, por exemplo, conserto do muro da escola, ar condicionado nas salas, rever a qualidade do lanche das crianças, ausência de estagiárias no projeto de escola de tempo integral, dentre outros.

c) necessidades no trabalho pedagógico. Esse item envolveu muitas necessidades e o grupo dividiu os temas para facilitar a continuidade dos trabalhos. Foram identificadas quatro temáticas que dificultam - trabalho pedagógico desenvolvido na escola, a saber: indisciplina; parceria pais e famílias, planejamento curricular e festas na escola.

O terceiro momento da dinâmica consistiu em decidir as ações para resolver as necessidades da escola apontadas pelos sujeitos. Em relação às necessidades apontadas no item "a" foi realizada uma lista identificando as prioridades que seriam encaminhadas para a compra, passando primeiro pelo Conselho de Escola. As 
necessidades referentes ao item " $b$ " seriam encaminhadas via ofício a Secretaria Municipal da Educação pela diretora, com a colaboração do secretário solicitando auxílio e providências.

No item " $c$ " organizamos quatro grupos para refletir as questões apontadas e elaborar ações para resolver ou minimizar as necessidades, estabelecendo prazos, sujeitos responsáveis e resultados esperados. A partir das propostas apresentadas pelos grupos e aprovadas no coletivo identificamos como necessidades formativas às temáticas: indisciplina; parceria pais e famílias e planejamento curricular de Língua Portuguesa e Matemática. Essas necessidades formativas subsidiaram a elaboração de uma ação de formação continuada para o ano letivo de 2014 na escola.

\section{AÇÃO DE FORMAÇÃO CONTINUADA DA} EQUIPE GESTORA

A formação continuada visa proporcionar aos educadores um processo constante do aprender, do repensar as suas práticas e do construir novos conhecimentos, que se constituem "por meio do estudo, da reflexão, da discussão e da confrontação das experiências dos professores", sendo de responsabilidade da instituição, mas também do próprio educador, afinal "o compromisso com a profissão requer que ele tome para si a responsabilidade com a própria formação" (LIBÂNEO, 2001, p. 191).

No entanto é preciso que a formação continuada se desenvolva "num processo articulado fora e dentro da escola". A prática da formação continuada "no cotidiano da escola apresenta muitos pontos positivos, mas por outro, a saída dos educadores para outros locais formadores também pode ser bastante enriquecedora" (FUSARI, 1997, p. 168).

A formação continuada com a equipe gestora se desenvolve no Projeto de Extensão/PROEX/UNESP em encontros de 4 horas de duração. No período de março a julho de 2014 realizamos oito encontros focando os temas indisciplina e planejamento. A formação continuada ocorre mediante discussões, estudos de textos e reflexões sobre o cotidiano da escola, que visa proporcionar um conhecimento científico a todos os envolvidos formando uma base sólida, que pode provocar mudanças nas ações dos educadores para a melhoria da qualidade do ensino oferecido na escola. Para tanto, os encontros de formação se tornam espaços para reflexão e busca de soluções para os desafios enfrentados no dia-a-dia da escola. Enfim é uma reflexão da realidade da escola, pois

[...] não basta saber sobre as dificuldades da profissão, é preciso refletir sobre elas e buscar soluções, de 
preferência, mediante ações coletivas. Segundo Philippe Perrenoud, a reflexão possibilita transformar o mal-estar, a revolta, o desânimo, em problemas, os quais podem ser diagnosticados, explicados e até resolvidos com mais consciência, com mais método. Ou seja, uma prática reflexiva [...] leva a uma relação ativa e não queixosa com os problemas e dificuldades. (LIBÂNEO, 2001, p. 190)

Durante a formação com os gestores no primeiro semestre, quatro reuniões focaram o tema da indisciplina, utilizando diversos autores como Aquino (2000); Franco (2009); Vasconcellos (2009). Nossas ações resultaram nas seguintes atividades: 1 . Retomada do que a escola parceira já desenvolveu sobre o tema indisciplina. 2. Leitura e discussões de pequenos textos subsidiado com reflexões sobre os desafios enfrentados no cotidiano da escola pela equipe gestora, professores e funcionários. 3. Mediante leitura prévia de textos sobre indisciplina, cada um apresentou suas colocações sobre as relações das idéias dos autores com o cotidiano da escola. Posteriormente elaboramos uma síntese com as idéias centrais dos textos lidos e discutidos. 4. Elaboramos algumas ações a serem desenvolvidas junto aos professores no ano letivo na escola sob orientação do coordenador pedagógico. 5. Na avaliação dessa ação constatamos a necessidade de uma fala de um professor convidado sobre o papel da equipe gestora, dos professores e dos funcionários sobre a indisciplina, que será planejado para o $2^{\circ}$ semestre.

Os outros quatro encontros foram dedicados ao tema planejamento, subsidiados por Libâneo (1994); Guimarães; Marin (1998) e Vasconcelos (2014). Nossas ações resultaram nas seguintes atividades: 1 . Retomada do que a escola já desenvolveu. 2 . Mediante leitura prévia de textos sobre planejamento, cada um apresentou suas colocações sobre as relações das idéias dos autores com o cotidiano da escola. 3. Analise do Projeto Político Pedagógico (PPP) da Escola com sugestões de alterações. 4. Discussão do Plano de Ensino (PE) de Matemática utilizado na escola com auxílio de um professor especialista na área da universidade, juntamente com os professores. 5. Reelaboração dos Planos de Ensino de Matemática.

\section{DISCUSSÃO}

Defendemos a gestão democráticoparticipativa como necessária para a qualidade no ensino público, visto que enfatiza "a participação de todos nas decisões, em discussão aberta e pública de fatos, com confiança e respeito aos outros" (LIBÂNEO, OLIVEIRA, TOSCHI, 2003, p. 383). 
Nesta gestão, essencialmente, é muito importante a integração dos membros da equipe escolar no momento da análise dos problemas, nas decisões, na reflexão e no encaminhamento de possíveis soluções para os desafios que aparecem cotidianamente na escola. Todos assumem uma responsabilidade e segundo Libâneo, Oliveira e Toschi (2003, p. 350)

[...] o diretor e o
coordenador pedagógico
assumem papel de
coordenadores de ações
voltadas para objetivos
coletivamente
estabelecidos. [...]. Para
isso, precisam reconhecer
que sua ocupação tem uma
característica
genuinamente interativa,
ou seja, está a serviço das
pessoas e da organização,
delas requerendo uma
formação especifica a fim
de buscar soluções para os
problemas, saber coordenar
o trabalho conjunto[...].

$\mathrm{Na}$ formação continuada com a equipe gestora concluímos que o tema indisciplina é um desafio de quase todas as escolas, sejam municipais, estaduais ou particulares. Desse modo, faz-se essencial que equipe gestora enfrente esse desafio, compreendendo seu conceito, suas causas e buscando elaborar soluções coletivas para resolvê-lo.

A indisciplina atualmente não possui apenas uma causa, por isso é necessário análise e estudo reflexivo do cotidiano da escola. Para amenizar o problema, que tanto dificulta o trabalho na escola é preciso que haja um trabalho constante com toda a comunidade escolar, inclusive os pais, focando as causas da indisciplina, com palestras com especialistas, leituras de textos que tragam projetos que deram certos em outras escolas, vídeos, construção de projetos com as crianças, etc. É importante também que haja a participação do professor coordenador pedagógico dentro das salas de aula, orientando e dando suporte para os professores.(FRANCO, 2009).

Entretanto, os especialistas enfatizam o papel dos profissionais da educação. Franco (2009, p. 169) afirma que

[...] respeitar o aluno na sua individualidade, garantir espaços para sua participação e respeita-lo como pessoa são aspectos que devem ser garantidos na escola e, quando não são desenvolvidos a contento, podem desencadear focos de indisciplina que, na verdade, são a maneira que os alunos encontram para buscar espaço, reconhecimento e respeito.

Conforme Aquino (2000), a indisciplina é um sintoma de que algo não está bem na relação pedagógica entre professor e aluno.

[...] nesse sentido, a gênese da indisciplina não residiria 
na figura do aluno, mas na rejeição operada por praticas incapazes de aglutinar as novas formas de existência social concreta, personificadas nas transformações do perfil da clientela escolar. Indisciplina então seria um dos sintomas (talvez o mais flagrante) da injunção de uma escola idealizada e gerida para um determinado tipo de clientela e ocupado por outro. (AQUINO, 2000, p.87).

No tema planejamento constatamos como a teoria pode contribuir na análise de problemas reais e na elaboração de propostas. Em nossa formação os gestores afirmaram como a leitura e discussões dos textos auxiliaram a ter mais clareza da articulação entre PPP, PE e Plano de Aula (PA). Para Libâneo (1994, p. 221) “o planejamento é um meio para se programar as ações docentes, mas é também um momento de pesquisa e reflexão intimamente ligado a avaliação".

Compreendemos que o PPP é o principal documento da escola tendo em vista uma educação de qualidade. O PPP é flexível e pode ser adequado conforme a necessidade de cada escola.

O plano da escola é o plano pedagógico e administrativo da unidade escolar, onde se explica a concepção pedagógica do corpo docente, as bases teóricometodológicas da organização didática, a contextualização social, econômica, política e cultural da escola, a caracterização da clientela escolar, os objetivos educacionais gerais, a estrutura curricular, diretrizes metodológicas gerais, o sistema de avaliação do plano, a estrutura organizacional e administrativa". (LIBÂNEO, 1994, p. 230).

\section{A construção coletiva do PPP é uma} ação da gestão democrático-participativa e resulta uma clareza para todos os profissionais da educação sobre o seu papel na melhoria da qualidade do ensino público. No caso dos professores é essencial a compreensão de que sua atuação em sala de aula, mediante a elaboração do PA deve se originar do PE que precisa estar articulado com o PPP da escola.

Nesse sentido a análise, reflexão e reelaboração dos PE de Matemática envolvendo a equipe gestora, os professores, os alunos de graduação, o pesquisador e o professor especialista da área da universidade foi um momento excelente de formação e desenvolvimento profissional de todos. 


\section{CONCLUSÃO}

Nas conclusões enfatizamos dois aspectos essenciais nessa pesquisa.

Primeiramente a compreensão de que a qualidade das ações de formação continuada de professores ou demais profissionais está associada, dentre outros aspectos, ao nível de envolvimento e de participação destes em todas as fases da atividade formativa, desde o momento da identificação e análise das necessidades e da formulação da proposta de formação continuada até sua concretização e avaliação. Valorizar as necessidades formativas é uma primeira etapa do planejamento de ações de formação continuada, na medida em que orienta a formulação de objetivos e subsidia a definição de conteúdos e atividades. Os programas de formação continuada podem contribuir para o desenvolvimento profissional dos professores, desde que considerem efetivamente o seu papel, suas necessidades formativas e sua realidade educacional. (LIMA, 2013).

O segundo aspecto foca-se na importância da parceria entre a escola pública e a universidade. Elaborar parcerias significa unir indivíduos que estão interessados em trabalhar juntos para atingir objetivos comuns. Orsolon (2009, p.179) ressalta que a parceria representa 0 "encontro de diferentes para realizar um projeto comum [...]. A relação de parceria supõe confiança mútua e cumplicidade, isto é, conversas, trocas, discussões dos problemas e assunção conjunta das decisões tomadas". A parceria entre a universidade e a escola municipal pesquisada é essencial para a concretização da proposta de formação continuada.

Nos dias atuais, a educação brasileira pública municipal apresenta grandes desafios, principalmente após a municipalização das escolas a partir de 1990, visto que muitas Secretarias Municipais de Educação não estavam preparadas para assumirem o ensino fundamental. Nesse sentido a parceria entre a escola e a universidade possibilita a reflexão, discussão e soluções de muitos desafios do cotidiano escolar. Essa parceria se constitui excelente espaço de formação e desenvolvimento profissional de todos os sujeitos envolvidos, seja na escola (professores, equipe gestora, funcionários, alunos, famílias), ou mesmo na universidade (pesquisadores, professores e alunos de graduação, futuros gestores).

\section{REFERÊNCIAS}

AQUINO, J. G. Do cotidiano escolar: ensaios sobre a ética e seus avessos. 2.ed. São Paulo: Summus editorial, 2000.

\section{FUSARI, J.C. Formação Contínua de}

Educadores: um estudo de representações de coordenadores pedagógicos da Secretaria Municipal de Educação de São Paulo. 1997. 224 f. Relatório de Pesquisa. Faculdade de 
Educação, Universidade de São Paulo, São Paulo, 1997.

FRANCO, F. C. A indisciplina na escola e a coordenação pedagógica. In: PLACCO, V M N S, ALMEIDA, L R. ( org.). $O$ coordenador pedagógico e ao cotidiano da escola. São Paulo: Edições Loyola. 6. Ed. 2009. 167-175.

GUIMARÃES, C.M.; MARIN, F.A.D.G. Projeto Pedagógico: considerações necessárias a sua construção. Revista Nuances, V.IV, p.35-47, set.1998.

LIMA, V.M.M. Necessidades formativas docentes como subsídios para uma política de formação contínua em serviço. In: LEITE, Y.U.F.; MILITÃO, S.C.N; LIMA, V M M (Orgs). Políticas Educacionais e qualidade da escola pública. 1.ed. Curitiba, PR: CRV, 2013. p. 127154.

LIBÂNEO, J.C.; OLIVEIRA, J.F; TOSCHI, M.S. Educação Escolar: políticas, estrutura e organização. São Paulo: Cortez, 2003. 408 p.

LIBÂNEO, J.C. Organização e Gestão da Escola: teoria e prática. Goiânia: Editora Alternativa, 2001, 260 p.

LIBÂNEO, J.C. Didática. São Paulo: Cortez, 1994.

ORSOLON, L. A. M. Trabalhar com as famílias: uma das tarefas da coordenação. In: PLACCO, V M N S, ALMEIDA, L R. (Org.). 0 coordenador pedagógico e o cotidiano da escola. 6. ed. São Paulo: Edições Loyola, 2009, p. 177-183.

VASCONCELLOS. C. Indisciplina e disciplina escolar: fundamentos para o trabalho docentes. São Paulo: Cortez, 2009.

VASCONCELLOS, C.S. Planejar é antecipar ações para atingir certos objetivos. Revista Nova Escola. jan. 2009. Disponível em: http://revistaescola.abril.com.br. Acesso: 24.abr.2014.
Recebido para publicação em 30/07/2014 Revisado em 28/08/2014

Aceito em 01/09/2014 